\title{
The Fermilab 400-MeV Linac Upgrade
}

\author{
Charles W. Schmidt \\ Fermi National Accelerator Laboratory \\ P.O. Box 500, Batavia, Illinois 60510
}

May 1993

Presented at the 1993 Particle Accelerator Conference, Washington, D.C., May 17-20, 1993 


\section{Disclaimer}

This report was prepared as an account of work sponsored by an agency of the United States Government. Neither the United States Government nor any agency thereof, nor any of their employees, makes any warranty, express or implied, or assumes any legal liability or responsibility for the accuracy, completeness, or usefulness of any information, apparatus, product, or process disclosed, or represents that its use would not infringe privately owned rights. Reference herein to any specific commercial product, process, or service by trade name, trademark, manufacturer, or otherwise, does not necessarily constitute or imply its endorsement, recommendation, or favoring by the United States Government or any agency thereof. The views and opinions of authors expressed herein do not necessarily state or reflect those of the United States Government or any agency thereof. 
Preprint of paper presented at the 1993 Particle Accelerator Conference, Washington, D.C., (CEBAF), May 17-20, 1993.

\title{
The Fermilab 400-MeV Linac Upgrade
}

\author{
Charles W. Schmidt \\ Fermi National Accelerator Laboratory* \\ P.O. Box 500, Batavia, Ilinois 60510
}

\section{Abstract}

The Fermilab Linac Upgrade will increase the linac energy from $201 \mathrm{MeV}$ to $401.5 \mathrm{MeV}$. Seven accelerating modules, composed of $805-\mathrm{MHz}$ sidecoupled cells, will accelerate $\mathrm{H}^{-}$beams from 116.5 to $401.5 \mathrm{MeV}$. The side-coupled structure (SCS) has been built, tuned, tested to full power, and placed in the linac enclosure along side the operating Linac. All seven accelerating modules, each containing four sections of sixteen cells, have been connected to 12-MW power klystrons and tested to full power for a significant period. The transition section to match the beam from the 201.25-MHz drift-tube linac to the SCS, consisting of a sixteen-cell cavity and a vernier fourcell cavity, has also been tested at full power. A new transport line from the Linac to the Booster synchrotron with a new Booster injection girder is to be installed. Removal of the last four Alvarez linac tanks (116.5 to $201 \mathrm{MeV}$ ) and beam-line installation of the Upgrade components is to begin in early June 1993 and should take about 12 weeks. Beam commissioning of the project will follow and normal operation is expected in a short period. In preparation for beam commissioning, studies are being done with the operating linac to characterize the beam at transition and prepare for phase, amplitude and energy measurements to commission the new linac. The past, present and future activities of the 400-MeV Upgrade will be reviewed.

\section{Introduction}

The present Fermilab Linac is an Alvarez-type drift-tube (DT) linac consisting of nine cavities operating at a frequency of $201.25 \mathrm{MHz}$ that accelerates $\mathrm{H}^{-}$ions to $201 \mathrm{MeV}$. The Linac operates for Booster injection at a maximum rate of 15 pulses-per-sec with a pulse length of $30 \mu \mathrm{s}$ and an intensity of $35 \mathrm{~mA} \mathrm{[1].} \mathrm{At}$ present the Booster intensity is limited to approximately $3 \times 10^{12}$ protons-per-cycle due to a large space charge tune shift during injection. Increasing the energy to $400 \mathrm{MeV}$ should allow beams of higher brightness or intensity. Preserving this improvement through the followisig accelerators will give higher production rates for antiprotons, higher brightness and greater luminosity for colliding beams, and higher intensity for fixed-target experiments. The Main

\footnotetext{
* Operated by the Universities Research Association, Inc. under contract No. DE-AC02-76CH03000 with the U.S. Department of Energy.
}

Injector Project is intended to take full advantage of this improvement [2].

To achieve $400 \mathrm{MeV}$ the present linac will be modified by removing the last four cavities and replacing them with $805-\mathrm{MHz}$ side-coupled modules [3-6]. The 200-MeV DT linac will end at $116.5 \mathrm{MeV}$ (Cavity 5) to inject into the side-coupled structure. The first section of the SCS is an $805-\mathrm{MHz}$ transition module for longitudinally matching the beam into the first SCS accelerating module. Seven SCS accelerating modules will take the beam to $401.5 \mathrm{MeV}$. The new structure, which is $63.7-\mathrm{m}$ long, about $3 \mathrm{~m}$ shorter than the old cavities, fits within the present enclosure allowing for a new transport line to the Booster. The SCS therefore operates at approximately three times the average accelerating gradient of the older linac.

The SCS is composed of seven modules, each assembled from four 16-cell sections and three bridgecouplers. Power for each module is fed to the center coupler. Each module is powered by a $12-\mathrm{MW}, 805-$ $\mathrm{MHz}$ klystron. The nominal peak power for each module with $35 \mathrm{~mA}$ of beam is about $10 \mathrm{MW}$. The new structure is designed to accelerate up to $50 \mathrm{~mA}$ of beam.

\section{General Design}

Considerations for the project began in 1986 following studies and realization that the Booster was limited at injection and could be improved by increasing the Linac energy [2]. Several linac structures were reviewed and doubling of the Linac energy to give a significant improvement in the Booster appeared possible.

Two structures were carefully investigated through studies and by building models that were tested to high If power. One, the disk-and-washer was considered for its efficiency and strong coupling however its mode structure and construction appeared uncomfortably complex $[7,8]$. The other, the side-coupled structure, appeared easier to build, better understood, and has a proven history as demonstrated at Los Alamos. The SCS was chosen.

The Project began in earnest in 1989 with approval from the DOE. Refinements of the basic design parameters were done using the SCS to achieve the desired energy within constraints of the present tunnel length. By dividing the accelerator into seven accelerating modules, each with four sections of sixteen cells, a solution was found that gave acceptable surface fields, divided the accelerator into sections that minimized the mechanical variables, gave 
approximately equal power to each module, and achieved an acceptable transverse focusing condition (see Table 1) [9]. Studies on early prototype cavities gave an indication that a spark rate of one per thousand for the total structure could possibly be achieved [10] corresponding to an acceptable beam loss of $0.1 \%$. Refinement of the nose-cone shape led to a significant reduction in the maximum surface field and surface area with little effect on the shunt impedance. This significantly reduced the sparking rate.

\section{Table 1. General Design Parameters}

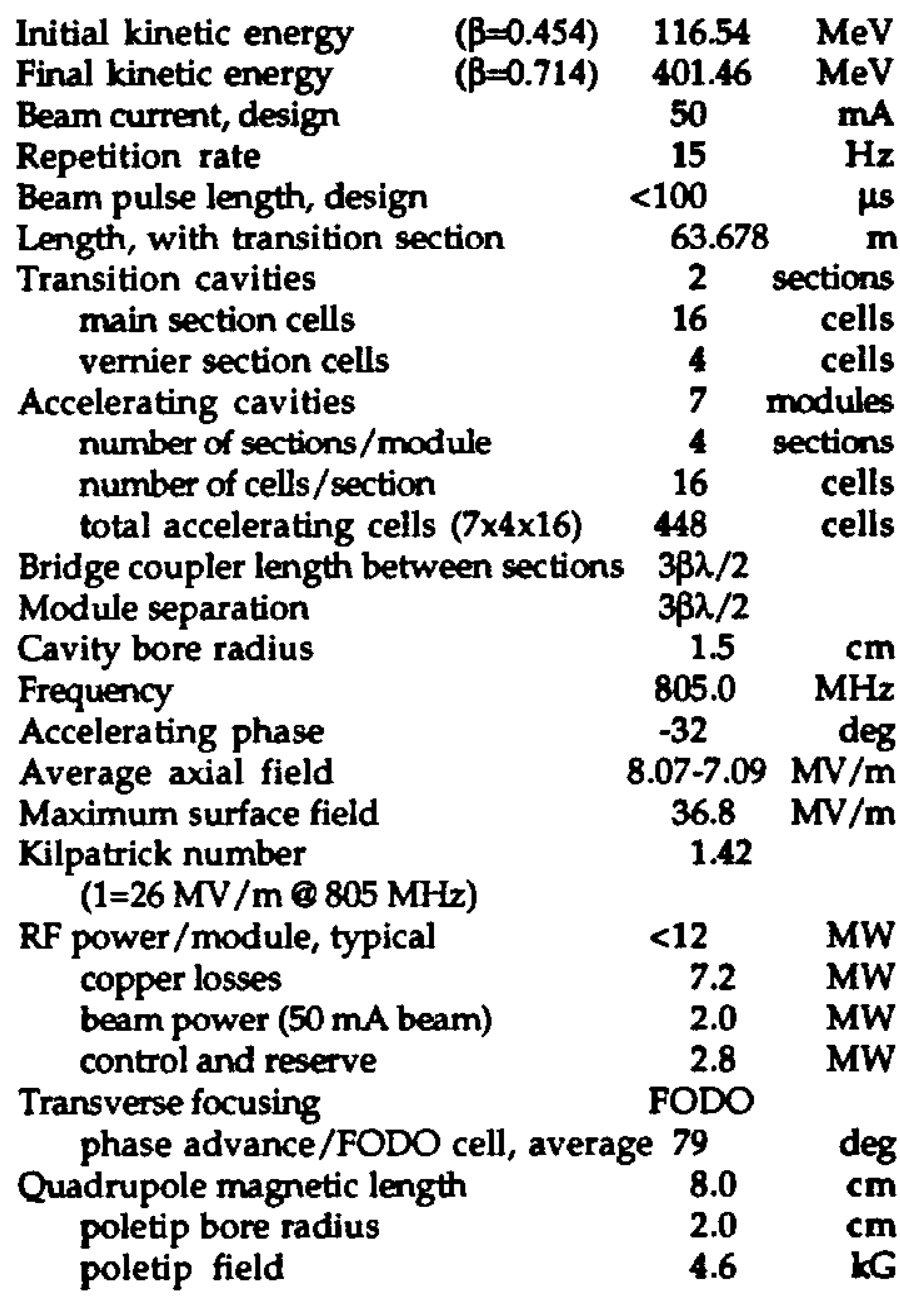

\section{Mechanical Design}

A mechanical design was chosen that would allow machining of call regments from class 1 OFHC copper using computer controlled machines to give close tolerance and optimum surface finish. The copper was obtained from Hitachi Industries. The segments were assembled in successive steps by furnace brazing to form a section of sixteen cells (see Figure 1) [11].

All cells are identical within a section with the cell length corresponding to the average velocity for the section. The cell dimensions were computed using the SUPERFISH code and tested for frequency using aluminum models. The modeling allowed for small corrections that could be fed into the final dimensions for the copper cells [12]. The design proved to be sufficiently accurate and reproducible that the final sections and modules required minimal tuning in their final stages $[13,14]$.

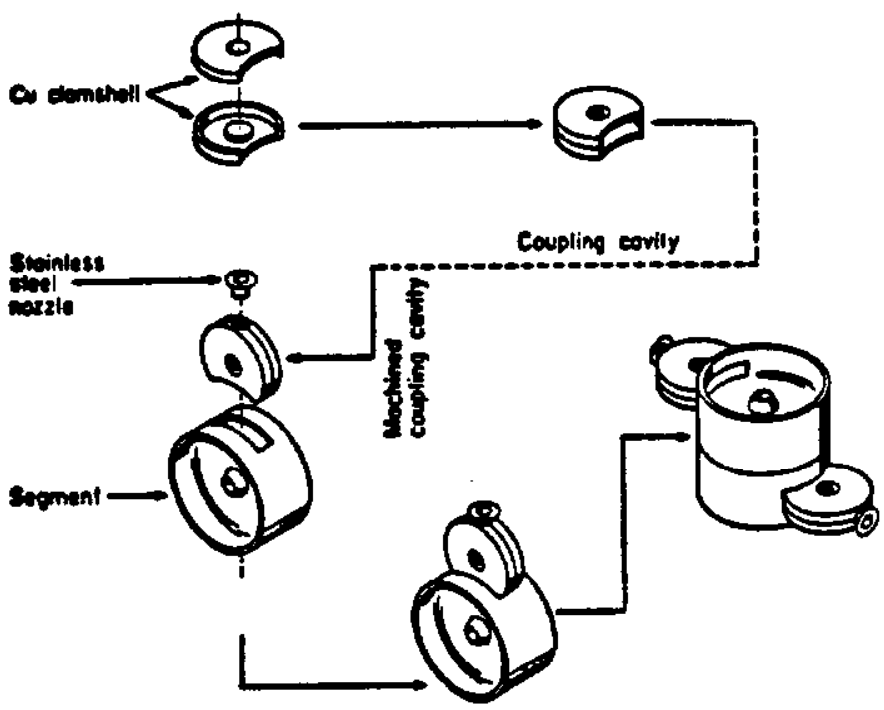

Figure 1. Side-coupled cavity construction.

The section ends and the bridge coupling cavities required special attention because of their different geometry and unique coupling flange. They require more tuning and specialized machining to arrive at the correct frequency.

\section{Radio-Frequency Systems}

Each of seven modules of the Linac Upgrade requires a $12-\mathrm{MW}, 805-\mathrm{MHz}$ if system to power the cavities and accelerate beam. A 12-MW klystron is the center piece of each system powered by a charging supply and an SCR-switched PFN modulator through a 20:1 step-up transformer. The maximum klystron voltage is $180 \mathrm{kV}$ at $15-\mathrm{Hz}$ rate and a pulse length of $125 \mu \mathrm{s}$. The pulsed current is $150 \mathrm{~A}$. The klystron was developed by Litton Electron Devices (L-5859 klystron) for this project.

The rf output is controlled by the input If drive to the klystron. With a gain of $\sim 50 \mathrm{~dB}$ the input power is $\sim 100 \mathrm{~W}$ from the low-level system. The low-level system, a VXI based system, monitors the module amplitude and phase to maintain set conditions for accelerating beam. Besides standard feed-back from the modules, learning programs using the error signal are used to improve the pulse wave-form [15].

The transition sections and a "debuncher" [16], an energy corrector in the transport line to the Booster, are powered by three smaller commercial 200-kW klystrons from Varian Associates. 


\section{Computer Controls}

A new control system was installed for the Fermilab Linac and the Linac Upgrade. This control system was implemented for the Linac Upgrade and installed for the operating Linac in early 1992. It has been a very useful system. The system uses a TokenRing network to interconnect several VMEbus crates (Local Stations) to each other and through a bridge to the central accelerator control system. The VME crates contain hardware to communicate with the network and control the Linac at $15-\mathrm{Hz}$ rate. Local analog, digital, binary and timing control with the accelerator devices is accomplished by a "smart rack monitor" (SRM) containing a MC68332 microcontroller and interfaces to the VME crates via ARCnet links [17-19].

In addition to communicating with the Main Control Room consoles the Linac Local Stations support TCP/IP communications on Internet. This capability is used to communicate with Macintosh consoles located at the klystron control racks as well as with Macintosh and Sun workstations located in laboratories and offices of Linac personnel.

\section{Diagnostics}

The Linac Upgrade will incorporate several diagnostic devices to give the needed beam information for commissioning and operating the accelerator [20]. In the commissioning phase it is necessary to set the proper condition for transition of the beam from the 201-MHz DT linac to the 805-MHz SC linac, to set the correct amplitude and phase of each accelerating module, to center the beam in the aperture, and to measure the longitudinal and transverse properties of the beam especially at transition and output.

In the transition region there will be three horizontal and vertical wire scanners for measuring the emittance and Twiss parameters of the beam from tank 5 of the DT linac. This section will also contain two bunch length monitors of the secondary electron emission type [21] for measuring the longitudinal extent and density of the beam before and after the transition rotation.

In the accelerator sections the open spaces are only $3 \beta \lambda / 2$ between sections and modules or $14 \mathrm{~cm}$ to $40 \mathrm{~cm}$ from first to last section. In each section there is a quadrupole of $8.6-\mathrm{cm}$ length and between modules there is also a vacuum valve. Because of the closeness, the diagnostic elements have been selected and designed to fit into the remaining space. An rf beam position monitor (BPM) is located within each quadrupole to give the horizontal and vertical beam centroid. Only alternate planes in which the beam is large will be used initially. The BPM's together with strategically located horizontal and vertical trim steering magnets will be used to center the beam. Where possible, there are beam current toroids and beam wire scanners (about one per module). Similar devices will be located in the $400-\mathrm{MeV}$ diagnostic line and the transport line to the Booster.

Resistive wall-current monitors will be used for measuring the relative beam phase for establishing the rf amplitude and phase in each module. The correct if setting for a module can be determined by scanning the beam bunch phase some distance downstream of a module relative to a reference signal as the module phase is changed. Comparing the scanned signal for a full cycle to the theoretical curve will provide the if phase and amplitude for the module. This phase-scan match method is similar to the delta-t method but somewhat simpler to implement [22-24].

\section{Present Status}

Presently all the accelerating modules have been built, tuned $[25,26]$ and tested in a test concrete cave to shield for $\mathrm{X}$-rays using the prototype klystron. They were run to full power for an extended period until the spark rate was acceptable [27]. The spark rate decreased to acceptable levels with approximately 4$6 \times 10^{6}$ pulses (<1 week).

Early last year the transition section and all seven accelerating modules were placed in the Linac enclosure along side the DT tanks they will replace. They were connected for vacuum, water cooling and control, and if power and monitoring. As klystrons became available they were installed, and with the modules, operated at full power. All seven klystron rf stations and their respective modules have since been powered to full field, without beam, for an extended period [28]. This has given an opportunity to measure the characteristics of the rf systems, study the spark rate, and find early component failures and problems.

In general the system has performed well. Iritial difficulties with the prototype klystron have not been seen in the final production klystrons. Of eight production klystrons only one had a problem due to poor vacuum and has been returned. It did operate at full power and could have continued operating. The other klystrons have all gone to full power in short time ( 1 hour with experience) and continue to operate well. The klystrons now have a total of 25,000-hours operation with the longest being 7,000 hours $\left(375 \times 10^{6}\right.$ pulses). No production klystron has failed in service.

Problems have occurred with the charging transformers for the if modulator power supplies. These are due to design and construction errors and will be repaired before the linac goes into commissioning.

The smaller klystrons for the transition cavities have also been installed and operated.

For the Upgrade the computer control system is fully operational and the operations group monitors and controls the Upgrade If systems from the main 
control room.

\section{Installation and Commissioning}

Commissioning of the Upgrade is to begin late this summer following installation of the beam line components and required approval. As a minimum, the installation will require removing the last four tanks of the DT linac and associated equipment, moving the side-coupled modules from their present position in the enclosure to their final beam line location, installing the quadrupoles, diagnostics and beam control components, aligning the modules and quadrupoles, and reconnecting or connecting all components. At the same time the Booster group will remove and replace the transport line and Booster injection girder to handle $400-\mathrm{MeV}$ beams. All of this equipment has or will be tested without beam as fully as possible before installation. It is anticipated that installation will take -12 weeks.

Before and during installation the Laboratory will conduct a DOE required "Accelerator Readiness Review" for the Upgrade project to obtain DOE approval for commissioning and later for routine operation [29].

Once the new accelerating structure, transport line and all necessary equipment are in placed and fully operational, and all approvals are given, commissioning of the Upgrade with beam will commence. Initially, the beam current, pulse length and repetition rate will be set to a minimum but sufficient to observe beam. This will minimize the risk of damage and activation to the beam-line components during initial adjustments. Radiation safety protection to personnel areas outside the accelerator enclosure will be maintained by radiation monitors that will inhibit beam when indicated or by known sufficient passive shielding.

With low intensity, the quadrupoles will be set and adjusted to transport beam through the structure and to the dump. Beam current toroids, loss monitors, wire scanners, If beam position monitors, and trim steering magnets will also be used to monitor and adjust the beam. With beam transported through the structure and to the dump, the output of DT tank 5 and the transition section can be studied and adjusted. Once an acceptable match is obtained the modules of the accelerating structure can be successively turned on and tuned. For tuning the module of parameters a variation of the Los Alamos delta-t procedure, which has been termed the phase-scan match method, will be used. The phase-scan match method should be easier and sufficient for achieving our initial objective if accelerated beam. Beam time-of-flight and spectrometer momentum measurements will be used for necessary confirmation.

With low-intensity $400-\mathrm{MeV}$ beam achieved, more detailed studies can be done to improve the matching, steering and focus of the beam, improve the if parameter settings, and slowly raise the intensity and duty-factor. During this time the Booster $400-\mathrm{MeV}$ transport can be studied and tuned, and beam can be injected into the Booster.

Once sufficient $400-\mathrm{MeV}$ beam is established to the dump and Booster transport line, the shielding at the high energy end of the linac enclosure can be reassessed for the new beam energy.

The commissioning period is anticipated to take about $5-6$ weeks. Following commissioning the success of the program will be reviewed to obtain DOE approval for normal operation. The timely success of the installation and commissioning programs is important to the Laboratory's schedule and physics program. The second half of the present colliding beams (protons on antiprotons) program is to resume in the fall of 1993. It is obvious that the Linac Upgrade must be in operation for this to happen. Also, the increased intensity will be significant in reaching the antiproton production rate and the luminosity to carry out the physics program for this run.

\section{Acknowledgments}

As with any major project there are too many people to list individually, at least without missing some important contributors. I, and I am sure my close colleagues, express our appreciation to the many people at Fermilab and elsewhere that have worked on this effort and will see it through to completion.

\section{References}

[1] L. J. Allen, Arlene J. Lennox and C. W. Schmidt, "Operational Experience with the Fermilab Linac", Proc. 1992 Linear Accel. Conf., Ottawa, (Chalk River-AECL-10728), p. 82.

[2] Stephen D. Holmes, "Achieving High Luminosity in the Fermilab Tevatron", Proc. 1991 IEEE Part. Accel. Conf., San Francisco, (IEEE 91CH3038-7), p. 2896.

[3] D. E. Young and R. J. Noble, "400-MeV Upgrade for the Fermilab Linac", Proc. 14th Int. Conf. on High Fnergy Accelerators, Tsukuba, Japan, (Aug., 1989). Particle Accelerators, 1990, Vol. 26, p. 205.

[4] J. A. MacLachlan, "400 MeV Upgrade for the Fermilab Linac", Proc. 1989 IEEE Part. Accel. Conf., Chicago, (IEEE 89CH2669-0), p. 950.

[5] Robert J. Noble, "The Fermilab Linac Upgrade", Proc. 1990 Linear Accel. Conf., Albuquerque, (Los Alainos, LA-12004-C), p. 26.

6) Robert J. Noble, "The $400 \mathrm{MeV}$ Linac Upgrade at Fermilab", Proc. 1992 Linear Accel. Conf., Ottawa, (Chalk River-AECL-10728), p. 565.

[7] A. Moretti et al., "An $805 \mathrm{MHz}$ Disk and Washer 
Structure for the Fermilab Linac Upgrade", Proc. 1988 Linear Accel. Conf., Newport News, VI, (CEBAF-Report-89-001), p. 143.

[8] D. E. Young et al., "An $805 \mathrm{MHz}$ Disk and Washer Accelerating Structure with Coaxial Coupler for the Fermilab Upgrade", Proc. 14th Int. Conf. on High Energy Accelerators, Tsukuba, Japan, (Aug., 1989). Particle Accelerators, 1990, Vol. 26, p. 211.

[9] L. Oleksiuk, J. MacLachlan and F. Mills, "The Fermilab Upgrade Linac: Dynamics Design Process", Proc. 1990 Linear Accel. Conf., Albuquerque, (Los Alamos, LA-12004-C), p. 335.

[10] T. Kroc and A. Moretti, "Conditioning of High Gradient $\mathrm{H}^{-}$Accelerating Cavities", Proc. 1990 Linear Accel. Conf., Albuquerque, (Los Alamos, LA12004-C), p. 102.

[11] Michael P. May et al., "Mechanical Construction of the $805 \mathrm{MHz}$ Side Couple Cavities for the Fermilab Linac Upgrade", Proc. 1990 Linear Accel. Conf., Albuquerque, (Los Alamos, LA-12004-C), p. 105.

[12] Thomas G. Jurgens et al., "The Determination of the $805 \mathrm{MHz}$ Side Coupled Cavity Dimensions for the Fermilab Linac Upgrade", Proc. 1990 Linear Accel. Conf., Albuquerque, (Los Alamos, LA-12004C), p. 108.

[13] Harold W. Miller et al., "Tuning Methods for the $805 \mathrm{MHz}$ Side-Coupled Cavities in the Fermilab Linac Upgrade", Proc. 1990 Linear Accel. Conf., Albuquerque, (Los Alamos, LA-12004-C), p. 111.

[14] Peter Steven Prieto et al., "Side Coupled Accelerating Structure Automated Measurement System", Proc. 1990 Linear Accel. Conf., Albuquerque, (Los Alamos, LA-12004-C), p. 114.

[15] R. Pasquinelli and B. Chase, "VXI Based Low Level RF System for Fermilab Linac Upgrade", this conference.

[16] J. A. MacLachlan et al., "Feed-Forward Compensation for Transient Beam Loading of the $805 \mathrm{MHz}$ Debuncher for the Fermilab Linac Upgrade", Proc. 1990 Linear Accel. Conf., Albuquerque, (Los Alamos, LA-12004-C), p. 303.

[17] Elliott S. McCrory, Robert W. Goodwin and
Michael F. Shea, "Upgrading the Fermilab Linac Local Control System", Proc. 1990 Linear Accel. Conf., Albuquerque, (Los Alamos, LA-12004-C), p. 474.

[18] S. Shutirbu et al., "Smart Rack Monitor for the Linac Control System", Proc. 1991 IEEE Part. Accel. Conf., San Francisco, (IEEE 91CH3038-7), p. 1484.

[19] M. F. Shea et al., "ARCNET as a Field Bus in the Fermilab Linac Control System", Proc. ICALEPCS, Tsukuba, Japan, (Nov. 1991) p. 291.

[20] Elliott S. McCrory, Glenn Lee and Robert C. Webber, "Diagnostics for the $100 \mathrm{MeV}$ FNAL Linac", Proc. 1990 Linear Accel. Conf., Albuquerque, (Los Alamos, LA-12004-C), p. 456.

[21] Elliott S. McCrory, Charles W. Schmidt and A. V. Feschenko, "Use of an INR-Style Bunch-Length Detector in the Fermilab Linac", Proc. 1992 Linear Accel. Conf., Ottawa, (Chalk River-AECL-10728), p. 662.

[22] T. L. Owens et al., "Tuning Procedures for the Fermilab Linac Upgrade", this conference.

[23] Thomas L. Owens and Elliott S. McCrory, The Delta-T Tuneup Procedure for the Fermilab Linac", Proc. 1990 Linear Accel. Conf., Albuquerque, (Los Alamos, LA-12004-C), p. 721.

[24] M. B. Popovic et al., "Time-of-Flight Measurements of Absolute Beam Energy in the Fermilab Linac", this conference.

[25] Zubao Qian et al., "Final Module Tuning of the 805 $\mathrm{MHz}$ Side-Coupled Cavities for the Fermilab Linac Upgrade", Proc. 1992 Linear Accel. Conf., Ottawa, (Chalk River-AECL-10728), p. 422.

[26] Harold W. Miller et al., Tuning Summary for the $805 \mathrm{MHz}$ Side-Coupled Cavities in the Fermilab Linac Upgrade", Proc. 1992 Linear Accel. Conf., Ottawa, (Chalk River-AECL-10728), p. 419.

[27] T. Kroc, A. Moretti and M. Popovic, "Fermilab Linac Upgrade - Module Conditioning Results", Proc. 1992 Linear Accel. Conf., Ottawa, (Chalk River-AECL-10728), p. 187.

[28] Q. Kerns et al., "Performance of Litton $805 \mathrm{MHz}, 12$ MW Klystron", this conference.

[29] DOE Order 5480.25 . 